\title{
OS SIGNOS NÃO VERBAIS ENQUANTO PALAVRAS NA CONSTITUIÇÃO ENUNCIATIVA DO GÊNERO FÍLMICO
}

\author{
LEONARDO DE OLIVEIRA ${ }^{1}$ \\ LUCIMARA GRANDO MESQUITA ${ }^{2}$
}

\author{
Universidade Federal de Lavras - UFLA \\ Campus Universitário - Aquenta Sol, Lavras - MG, 37200-900. \\ loliveira10091@gmail.com, lucigrando123456@hotmail.com
}

\begin{abstract}
Resumo. $O$ Círculo de Bakhtin conceitua a enunciação como um processo em que se responde a algo anterior e suscita-se algo posterior. Dessa forma, toda enunciação só adquire sentidos a partir da interação, pois exige a existência de no mínimo dois sujeitos participantes dessa corrente enunciativa. Tal conceito também se aplica às linguagens não verbais, razão pela qual o presente trabalho propõe o estudo desses signos na constituição enunciativa do filme, tomando-os como palavras em sentido amplo. Nessa perspectiva, observaremos como aspectos não verbais presentes nas cenas iniciais do filme Kiriku e a feiticeira contribuem para constituição de uma unidade enunciativa a partir de uma abordagem com base nos pressupostos teóricos do Círculo de Bakhtin.
\end{abstract}

Palavras-chave: enunciado; não-verbal; Círculo de Bakhtin.

\begin{abstract}
Bakhtin's circle conceptualizes enunciation as a process in which something is answered earlier and something later is raised. In this way, every enunciation only acquires meanings from the interaction, as it requires the existence of at least two subjects participating in this enunciative current. This concept also applies to non-verbal languages, which is why the present work proposes the study of these signs in the enunciative constitution of the film, taking them as words in a broad sense. In this perspective, we will observe how non-verbal aspects present in the initial scenes of the film Kiriku $e$ a feiticeira contribute to the constitution of an enunciative unit from an approach based on the theoretical assumptions of the Bakhtin Circle.
\end{abstract}

Keywords: utterance; non-verbal; Bakhtin circle.

\footnotetext{
${ }^{1}$ Mestrando do Programa de Pós-Graduação em Letras (PPGL/UFLA) da Universidade Federal de Lavras (UFLA)

${ }^{2}$ Mestranda do Programa de Pós-Graduação em Letras (PPGL/UFLA) da Universidade Federal de Lavras (UFLA), bolsista CAPES.
} 


\section{CONSIDERAÇÕES INICIAIS}

O ser humano é eminentemente social e relaciona-se com os seus semelhantes através da linguagem. Mas ela não se limita a isso. Para além de veículo das trocas de informação, a linguagem, ou melhor, as linguagens, consistem nas bases socioideológicas sobre as quais os sujeitos constituem-se, conhecem-se mutuamente e compreendem o mundo, atribuindo sentidos a tudo o que lhes chega à consciência. Todas essas construções se dão em processos enunciativos nos quais os sujeitos se fazem entender a partir de materialidades sígnicas de diferentes naturezas socialmente partilhadas. Tendo essa perspectiva em mente, a proposta deste artigo é apresentar uma discussão acerca da constituição enunciativa a partir das semioses não verbais presentes no filme Kiriku e a feiticeira. Tomando como base os pressupostos teóricos do Círculo de Bakhtin, especialmente no que se refere ao conceito de enunciado/enunciação ${ }^{3}$, instância mediadora e constitutiva dos sujeitos nele envolvidos, analisaremos aqui os signos não verbais constitutivos do filme, comparando-os às palavras no processo enunciativo desse gênero multissemiótico.

A partir desses pressupostos, assume-se que toda enunciação só possui sentido na interação entre sujeitos, pois ela sempre responde algo dito anteriormente e, ao mesmo tempo, suscita uma resposta. Isso posto, é necessário compreendermos a relação que existe entre o autor, os personagens e os telespectadores durante a apresentação de um filme, ou seja, ao longo do seu acontecimento como enunciação, e, para um melhor entendimento a respeito desse processo, traremos o texto de Rodrigues (2017), o qual irá, entre outros aspectos, demonstrar como o filme e, principalmente, a relação existente entre esse e os espectadores envolvidos, acontece.

Organizamos este estudo da seguinte forma: primeiramente discorreremos sobre o conceito de enunciado/enunciação e, na seção seguinte, sobre a verbivocovisualidade, conceito com o qual buscaremos compreender a possibilidade de os sujeitos construírem sentidos quando inscritos em processos enunciativos caracterizados pela multiplicidade de materialidades sígnicas integradas. Finalmente, passaremos para a análise das cenas introdutórias do filme Kiriku e a feiticeira a partir da visão bakhtiniana mencionada.

\section{A ENUNCIAÇÃO NO PROCESSO DE INTERAÇÃO}

Para o Círculo de Bakhtin, as noções de alteridade e de diálogo são a alma de toda sua teoria, uma vez que o diálogo implica em relação mútua. Essa inter-relação processual entre os signos é o resultado da alteridade entre os sujeitos do discurso, implicando também na sua própria constituição. Não conseguimos nos constituir como sujeitos senão no encontro com o outro na (e pela) linguagem. Logo, o sentido atribuído aos signos só será definido no contexto em que são enunciados, num processo de construção desse sentido não se repete justamente porque o caráter contextual e de alteridade da enunciação a torna irrepetível.

\footnotetext{
${ }^{3} \mathrm{O}$ emprego de forma conjunta dos termos enunciado e enunciação se deve ao fato de que, para o Círculo de Bakhtin, as duas dimensões são indissociáveis, de modo que, quando eles figuram isoladamente nos seus textos, isso se dá de modo a enfatizar ora um segmento do contínuo discursivo, no caso do primeiro, ora o processo ao longo do qual esse segmento toma forma ao refletir e refratar enunciados-outros aos quais responde e provoca concomitantemente, no caso do segundo.
} 
Assim, para que palavra seja tomada em seu sentido discursivo, ela tem de ser percebida como muito mais que materialidade estritamente linguística. Ela precisa transcender a mera referenciação para alcançar condição enunciativa, representando nela sujeitos e pontos de vista em contato dialógico. Transpondo essa noção para o circuito enunciativo do filme, percebe-se que entre autores e espectadores são colocadas em interação diferentes representações, numa dinâmica em que dizeres tornam-se enunciados em razão da sua dependência da situação comunicativa. Daí, pode-se vislumbrar que o sentido não está na palavra, uma vez que ele depende do encontro entre a palavra minha e a do outro para alcançar tal condição. A ideia de que a palavra não carrega sentido $a$ priori nos leva a pressupor que ela seja neutra. Isso porque, em si mesma, ela pouco diz; ela é fruto da organização das relações humanas e, em sentido estrito, possui apenas significados referenciais sedimentados ao longo da história. Sobre esse contraponto entre a palavra "inerte" e a palavra "plena", Bakhtin aponta, em Gêneros do discurso, que "as palavras não são de ninguém, em si mesmas nada valorizam, mas podem abastecer qualquer falante e os juízos de valor mais diversos e diametralmente opostos dos falantes" (2016, p. 48). Somente a partir da atribuição de valor por sujeitos em diálogo, ela adquire alma enunciativa, dando vida a sentidos. Reforçando essa ideia, Volochinov afirma que "fora da enunciação, a palavra só existe no dicionário, mas nesse é uma palavra morta" (2013, p. 195). Com esse raciocínio, percebemos que, desde o início a palavra é permeada pela ideologia, mas é na alteridade que esse componente ideológico se mostra em ação e se perpetua, dando ensejo a infinitas atribuições de sentido. Produto da luta de classes, a palavra não só possibilita o diálogo entre os sujeitos, mas também se faz dialógica por eles e pelo contexto. Embora ideológica desde os seus primórdios, mas insuficiente se destacada de um enunciado, a palavra que nos interessa aqui é aquela que adquire a sua plenitude na enunciação, aquela que veicula valorações sobre a vida, sobre o mundo, sobre os sujeitos que dela fazem uso e sobre si própria. Nesse viés, um dos conceitos fundamentais da teoria do Círculo de Bakhtin, e que neste trabalho utilizaremos, é o de enunciado/enunciação, sobre o qual Volochinov afirma o seguinte:

Qualquer enunciação, também aquela escrita, completa, responde a alguma coisa e é orientada para uma resposta. Ela não é senão um anel da cadeia ininterrupta constituída pelas enunciações. Qualquer documento escrito continua o trabalho dos precedentes, polemiza com eles, espera uma compreensão ativa, responsiva, antecipa-a etc. (2013, p. 118).

Uma vez depreendido o enunciado como elo de uma corrente, pode-se pensar a aplicabilidade desse conceito ao estudo de uma obra cinematográfica. Assim como qualquer gênero estritamente verbal, é necessário considerar o filme como tendo um autor, uma temática, um local em que será transmitido, um público que o irá assistir e as posições socioideológicas dos seus interlocutores. Para Bakhtin (2011), essas informações externas são fundamentais para a compreensão do enunciado, sendo, em realidade, constituintes e determinantes das suas condições de produção, de circulação e de recepção. Como resultado disso, o enunciado se torna aberto à construção de sentidos diversos.

Já afirmamos que a linguagem humana só tem razão de existir num contato dialógico entre sujeitos. Todas as expressões enunciativas são orientadas para o outro, mesmo quando hipotético. E essa comunicação elabora os mais diversos tipos de 
enunciação. Segundo Volochinov, “[...] a essência efetiva da linguagem está representada pelo fato social da interação verbal, que é realizada por uma ou mais enunciações" (2013, p. 158).

A mudança das formas da linguagem depende, principalmente, do intercâmbio comunicativo social. "Qualquer situação da vida em que se organize uma enunciação, não obstante, pressupõe inevitavelmente protagonistas, os falantes. Chamaremos de auditório da enunciação à presença dos participantes da situação" (VOLOCHINOV, 2013, p. 159). O estudioso desenvolve a ideia de que, na vida, a enunciação é tanto a parte verbal expressa, como parte extraverbal não expressa, subentendida. Essa enunciação assume uma dada forma verbal durante o processo da interação que, enquanto unidade de comunicação discursiva, consiste na materialização de um tipo particular de intercâmbio comunicativo social que organiza a forma gramatical e estilística da enunciação e que é conhecida como gênero.

Nesse raciocínio, um tipo de intercâmbio comunicativo social é o da vida cotidiana, no qual a situação e o auditório provocam a linguagem interior que, por sua vez, se dirige para um exterior que faz parte da vida, mas que permanece em parte subentendida, seja quando realizado a partir de uma ação, seja quando é resposta verbal a outros participantes da enunciação. Nesse sentido, tanto o pedido quanto a ordem são exemplos desse tipo de intercâmbio e são modelados pela palavra do outro da mesma forma que são determinados pelos obstáculos encontrados pelo destinatário. Volochinov, ao observar a natureza da consciência e a sua inter-relação com a linguagem interior, assevera que "[...] nenhum ato de consciência pode ser realizado sem ela. Inclusive quando surge uma sensação puramente fisiológica - por exemplo, a sensação de fome ou sede - para "sentir" essa sensação, para tomar consciência dela" (2013, p. 146 - itálico e aspas originais). Em acréscimo à necessidade de expressão da consciência, a obra insere na citação acima uma nota de rodapé em que se esclarece: "quer dizer, com qualquer signo, palavra, gesto, desenho, símbolo etc.” (2013, p. 146). Tendo essas observações em mente, podemos estender a análise das enunciações, e consequentemente das palavras que as constituem, a outras semioses, como pretendido neste trabalho.

Existem, então, várias formas, verbais e não verbais, que servem tanto para uma conversa corriqueira e descontraída, quanto para uma conversa formal em um ambiente de trabalho ou acadêmico, por exemplo. Todos esses tipos de enunciações são organizados por um auditório que possui fórmulas para se adaptar a todos os lugares de enunciação, fórmulas estas expressas por meio de diferentes linguagens. Paralelamente, tais enunciações também se configuram em função dos projetos enunciativos de seus sujeitos, que fazem de antemão julgamentos acerca dos seus próprios lugares enunciativos, da enunciação em si, dos seus interlocutores e de todas as demais condições que os cercam.

O processo de formação desses gêneros cotidianos se compõe da enunciação feita pelo falante e a compreensão por parte do ouvinte, sendo que os elementos da resposta fazem parte dessa compreensão, ou seja, concordamos ou discordamos da fala do outro. Assim, toda forma de enunciação verbal ou não verbal se desenvolve sob a forma de diálogo em que o ouvinte não é imóvel e indiferente, ele é um interlocutor vivo e único e, por isso, toda expressão desse ouvinte representa para o orador uma resposta clara ao seu discurso. Volochinov ilustra essa questão explicando que sempre existe um ouvinte- 
interlocutor que deve ser levado em consideração pelo falante e que até mesmo as intervenções verbais mais íntimas, como um pensamento na mente de um falante, são direcionadas para um ouvinte em um auditório, ainda que imaginário. Portanto, todo discurso é dialógico, ou seja, é dirigido a outra pessoa; e essa relação pressupõe uma correlação sócio hierárquica entre os envolvidos em qualquer enunciação, não apenas verbal, mas também gestual. Tanto no monólogo quanto no diálogo, "a orientação social é uma das forças vivas organizadas que, junto com a situação da enunciação, constituem não só a forma estilística, mas também a estrutura puramente gramatical da enunciação" (VOLOCHINOV, 2013, p. 169). Essa orientação ao outro está também presente na forma corporal do homem, como na postura das mãos e no tom de voz, e são determinadas pelo auditório e pela valorização que lhe é dada. Dessa forma, em decorrência desse direcionamento, toda enunciação carrega como conteúdo um projeto de sentido, que se concretizará em toda a sua plenitude na alteridade.

Por esse caminho, a enunciação tem sempre uma parte verbal e outra parte não verbal e essa asserção implica em desdobramentos importantes a essa investigação, já que se dedica à análise de enunciações que agregam constituintes não verbais. Para compreender uma enunciação é preciso saber onde e quando ocorre, conhecer o tema da conversação e a relação entre os interlocutores e suas valorações. Portanto, os aspectos subentendidos da parte não verbal são: "o espaço e o tempo em que ocorre a enunciação - o "onde" e o "quando"; o objeto ou tema de que trata a enunciação - "aquilo de que" se fala; e a atitude dos falantes face ao que ocorre - "a valoração"” (VOLOCHINOV, 2013, p. 172). Nessa lógica, os sentidos de uma enunciação dependem de uma série de elementos extra verbais que, na enunciação, se tornam partes constituintes dela. Porém, a atribuição de sentido necessita de uma expressão material para que haja vínculo entre uma vontade enunciativa, a situação e seu auditório.

Completando essa linha de pensamento, Volochinov dá margem à extensão do conceito de enunciado/enunciação a outros sistemas de signos ao colocar que "ainda que a enunciação esteja privada de palavras, bastará o som da voz - a entonação - ou somente um gesto. Fora de uma expressão material, não existe enunciação, assim como também não existe a sensação" (2016, p. 173-174 - itálico original). Com base nessa ideia, podemos nos ater ao fato de que a manifestação enunciativa pode lançar mão de diferentes sistemas de signos para sua concretização. Se pensarmos no quanto nos utilizamos de gestos e expressões faciais quando nos comunicamos, fica evidente como essas outras semioses são igualmente passíveis de se manifestarem enunciativamente, sucedendo e desencadeando reações tal qual o signo verbal, estando ou não articulada a esse último.

A entonação, a seleção das palavras e sua disposição também interferem na produção dos sentidos de uma enunciação, estabelecendo ainda íntima relação com a situação e com o seu auditório. Esses três aspectos sofrem mudanças importantes conforme as características da situação e o peso social que se atribui ao interlocutor. Segundo Volochinov: "A situação e o auditório, como já dissemos, determinam, sobretudo a orientação social da enunciação e, finalmente, o próprio tema da conversação. A orientação social, por sua vez, determina a entonação da voz e a gesticulação" (2013, p. 180-181).

Todos os aspectos acima mencionados se fazem presentes no enunciado a ser analisado, porém com a particularidade de integrar toda uma série de elementos não verbais em sua constituição, formando um todo verbivocovisual. Com base nessa 
constatação, a análise de um trecho do filme estará centrada na observação da relevância semântica da integração entre essas semioses.

Outro ponto importante a se destacar, é quanto ao enunciado verbivocovisual. Segundo Paula e Serni (2017), esse termo foi criado, inicialmente, para tratar da linguagem da poesia concreta e foi tomado de empréstimo pelos estudos bakhtinianos para explicar a manifestação enunciativa de diferentes semioses. Nessa linha, a verbivocovisualidade diz respeito às dimensões sonora, visual e dos sentidos das enunciações, constatação para qual se encontra sustentação teórica, entre outros trechos, na passagem de Os gêneros do Discurso em que Bakhtin conclui que:“[...] toda compreensão plena real é ativamente responsiva e não é senão uma fase inicial preparatória da resposta (seja qual for a forma em que ela se dê)" (2016, p. 25-26). A asserção do filósofo abre possibilidades à apreciação das linguagens não verbais e, portanto, pautará a observação de uma série de elementos inerentes à expressão cinematográfica, pensada enquanto enunciação concreta.

Roteiros, enquadramentos, planos, paletas de cores, trilha sonora, ações de personagens, cenários, entre muitos outros que integram um longa de animação são informações importantíssimas à compreensão da enunciação fílmica em sua totalidade, razão pela qual se toma aqui todos esses elementos mencionados como signos tão dotados de potencialidade semântica e enunciativa quanto o signo verbal, visto que eles todos têm a mesma capacidade de desencadear a construção de sentidos no todo desse gênero discursivo e coexistem numa unidade enunciativa indissolúvel.

\section{GÊNERO FÍLMICO: UMA QUESTÃO DE ALTERIDADE}

A relação existente entre os sujeitos não é possível de ser discutida sem passar pela questão da interconstituição recíproca na (e pela) linguagem. Tendo isso em mente, pensamos que durante a apresentação de um filme são estabelecidos intercâmbios discursivos não só entre o filme, enquanto "turno de fala" acabado, e o espectador, mas entre esse último, a equipe de produção e os personagens, interpelados pela linguagem cinematográfica. Existe então uma relação criada entre os envolvidos em todo o processo da enunciação do filme e que, a partir de linguagens verbivocovisuais irá permitir o enriquecimento da constituição intersubjetiva de todos eles.

Rodrigues (2017), embora tome como base o gênero cinematográfico documental, demonstra como os sujeitos envolvidos no circuito enunciativo do filme cocriam esse gênero na alteridade, conforme o trecho que segue: "[...] há uma relação dupla constituidora dos sujeitos (personagem/documentarista), que ao estabelecerem na linguagem esse universo formador e constituidor, possibilitam juntos os alicerces para a criação de uma obra artística [...]” (p. 125).

Assim, a mobilização dos signos presentes no filme resulta da interação de um grupo de sujeitos criadores cujo projeto enunciativo é a produção de um objeto estético destinado a espectadores que ocupam diferentes lugares sociais e, consequentemente, reagem de formas particulares. Logo, um filme produzido e destinado por e para sujeitos tão diversos entre si deve, no que tange os seus componentes verbivocovisuais característicos, fazer com que quem o assiste perceba a mensagem que se quer passar pela 
articulação entre semioses que precisam ser apropriadas de modo a constituírem um todo coeso e traduzível em efeitos de sentido para eles.

Segundo o cineasta, “[...] para entendermos esses possíveis diálogos, é necessário pontuar os participantes" (2017, p. 126). A partir dessa consideração, precisamos elencar os principais envolvidos na apresentação de um filme. Assim, temos o personagem, ou o Herói para Bakhtin, que será o sujeito cuja construção começa bem antes das filmagens, fruto do diálogo entre produtor e ator. Rodrigues (2017) ressalta que os enunciados que serão produzidos pelos personagens podem significar a voz da experiência ou a voz do saber. A primeira mostra algo vivido pelo ator e não poderá gerar dúvidas durante a narrativa, uma vez que seu enunciado revela algo sentido no corpo e que será dividido com o roteirista e com os espectadores. Já a segunda é utilizada pelo personagem para demonstrar o conhecimento que este possui e será utilizado para justificar os seus pensamentos e as ações. Além dessas, existem várias outras possibilidades que vão surgindo e que estão relacionadas à cena e às condições presentes no momento das filmagens.

Durante a produção de um filme pode-se criar diversas possibilidades no que diz respeito ao envolvimento do autor com a formatação dos personagens. De acordo com Rodrigues (2017), o autor enfrenta problemas de natureza ética e epistemológica na sua relação com o personagem, já que constrói a narrativa baseado na relação que tem com ele. Dado o caráter potencialmente criador do autor, este deve ponderar acerca do equilíbrio da sua interação com o personagem, pois a preponderância muito acentuada de uma ou outra parte, em certa medida, sacrifica o dialogismo da obra. No tocante a essa inter-relação autor-personagem, Bakhtin considera que:

[...] o autor não só enxerga e conhece tudo o que cada personagem em particular e todas as personagens juntas enxergam e conhecem, como enxerga e conhece mais que elas, e ademais enxerga e conhece algo que por princípio é inacessível a elas, e nesse excedente de visão e conhecimento do autor, sempre determinado e estável em relação a cada personagem, é que se encontram todos os elementos do acabamento do todo, quer das personagens, quer do acontecimento conjunto de suas vidas, isto é, do todo da obra (2011, p. 11).

Bakhtin então vê o autor fora e acima do lugar do personagem, cujo sentido da existência deve ao primeiro. Essa onisciência e onipotência do autor põe em pauta questões éticas que irão perpassar a sua visão a partir do momento em que ele se estabelece como sujeito de diálogos com personagens. $\mathrm{O}$ autor tem sempre autonomia sobre a obra, mas, a depender dos fins dela, pode outorgar aos personagens $\mathrm{o}$ encaminhamento das suas existências no desenrolar do enredo. Assim, os diretores podem ou não incorporar o seus valores a sua narrativa. Da mesma forma que questões éticas estão presentes no enredo, situações técnicas e de produção, relacionadas à forma e ao conteúdo, no qual outros sujeitos estão envolvidos, também se fazem presentes nesse cenário. No entanto, é necessário ao roteirista o controle dessas situações em nome da honestidade tanto para com o seu material quanto para com as personagens e os espectadores.

Essa relação entre o roteirista e o personagem não é uma relação tranquila e autônoma, pois é a imprevisibilidade que vai, aos poucos, moldando a forma que a trama 
vai tomando e isso acontece mesmo o autor tendo um controle sobre a obra. As escolhas do autor e de toda a sua equipe exercem enorme influência no ponto de vista criativo da obra que, enquanto ato responsável, não pode se sobrepor totalmente aos dos personagens do filme, sobretudo se considerarmos a sua orientação social.

Nesse sentido, temos também uma presença em uma obra cinematográfica que quase sempre não é percebida, que é o espectador. Esse traz consigo sua experiência de vida particular, que o levará a refletir de forma singular à apreensão da obra, provocando suas próprias interpretações no diálogo com a mesma. Esse espectador, enquanto consciência responsiva, também irá atuar como produtor de discursos a partir da mobilização que fará da sua memória e das suas vivências para compreender o enunciado. Assim, não será um destinatário passivo do filme, mas um produtor de sentidos ativamente criador de respostas que surgirão da relação com o enunciado e com os outros sujeitos dessa enunciação.

Todos esses pontos foram aqui levantados para demonstrar com clareza como os filmes, de um modo geral, acontecem enquanto enunciações. $O$ filme, cujo pequeno extrato aqui observaremos, embora seja uma animação, é dotado de características que o aproximam de qualquer longa filmado, pois o encadeamento das cenas, segmentadas em tomadas, simulam uma filmagem real. Dessa forma, o observamos praticamente da mesma maneira como faríamos com qualquer outro longa rodado em película.

Deslocando o pensamento do documentarista para a animação, entende-se que a criação dos personagens em um longa desse gênero assemelha-se ainda mais à criação estética nos termos em que Bakhtin analisa a composição de heróis no âmbito do romance, pois a concepção e o encaminhamento dado a personagens que não são interpretados por atores confere maior liberdade criativa àqueles que os idealizam. Esse aspecto se mostra de forma mais ressaltada na materialização do projeto enunciativo cinematográfico em função do público e de todas as demais condições dos circuitos enunciativos em que se instaura. É aqui que as escolhas dos sujeitos ligados à produção do longa se traduzem na configuração do seu conteúdo temático, do seu estilo e da sua estrutura composicional, conforme veremos adiante e, para análise dessas escolhas enunciativas, definimos como recorte para esse estudo as cenas introdutórias do filme, com cerca de dois minutos de duração, para observarmos como os seus elementos não verbais integram o enunciado fílmico de modo a situar discursivamente os interlocutores que põe em jogo.

\section{KIRIKU E A FEITICEIRA: UMA BREVE SINOPSE}

A obra cinematográfica dirigida por Michel Ocelot (1998) é uma animação franco-belga de 74 minutos que narra a história de um pequeno herói negro de uma comunidade africana subjugada por uma feiticeira. Rica em elementos característicos da etnia de Kiriku, a obra retrata aspectos daquele povo, como as suas crenças, o seu modo de vida, o papel da mulher nesse contexto, seus cantos, rituais, entre outros costumes desse grupo étnico.

Ressaltando as peculiaridades dessa cultura, são usadas cores fortes e vivas para retratar as paisagens, as roupas e os acessórios dos personagens, simbolizando elementos comuns a muitas culturas africanas. No filme, os cânticos figuram não apenas como parte 
da trilha sonora, mas caracterizam a musicalidade a tribo. As letras deles, por sua vez, denotam juízos de valor em relação ao protagonista e são cantadas pelos personagens de modo a caracterizar um aspecto marcante do dia a dia dessa comunidade, na qual o canto improvisado, acompanhado de instrumentos tradicionais e de danças típicas é recorrente na celebração de certos acontecimentos. Da mesma forma, o filme apresenta traços comportamentais dos personagens da forma mais próxima possível da realidade da tribo e, consequentemente, das culturas africanas.

Um ponto interessante retratado na obra cinematográfica é a presença de um herói diferente daqueles do cinema clássico, geralmente corpulento, com poderes mágicos ou aparatos tecnológicos empregados no combate de seus inimigos. Aqui, o herói Kiriku é sui generis, pois é um bebê pequeno, frágil, que antes mesmo de nascer já conversava com a sua mãe, e que usa de sua inteligência e esperteza incomuns para combater uma feiticeira perspicaz que amaldiçoa a sua terra. A maldade a que a vilã submete a sua tribo leva o pequeno herói a pensar constantemente no porquê da maldade das pessoas e das condições de vida do seu povo. Indignado com a miséria em que vive, se engaja em uma luta solitária contra aquele status quo e, na jornada ousada em que acaba se lançando, encontra pouco a pouco respostas para as questões que tanto o inquietam.

A empreitada do herói é bem sucedida e está atravessada por toda uma série de valores morais caros não só a sua cultura, mas à humanidade, o que angaria a identificação do espectador. Kiriku burla o sistema estabelecido para encontrar-se com o sábio da montanha anunciado por sua mãe e que, segundo ela, poderia fornecer-lhe as soluções que procura. Para alcançar tal façanha, enfrenta inúmeros perigos, doa-se de corpo e alma a sua causa e, ao final da sua aventura, consegue não só a libertação do seu povo da tirania da feiticeira como ainda a ajuda a desvencilhar-se da maldição que a acometia, convertendo-a ao bem. Esse herói diferente, com o seu altruísmo desmedido, é capaz de amar essa outrora inimiga e, recebendo um beijo dela, torna-se de repente adulto e até se casa com ela.

\section{KIRIKU E A FEITICEIRA: UM FRAGMENTO À LUZ DA VISÃO BAKHTINIANA}

Feita a contextualização, passemos agora ao segmento do filme que nos interessa. Ele se inicia com um plano aberto de uma pequena tribo que, com a simulação de movimento de câmera, gradativamente se fecha, aproximando-se das cabanas ao fundo. Nesse movimento, a câmera simulada passa por entre árvores secas, em seguida ao lado de um grande baobá perto do quais duas mulheres com vestes características trituram grãos em um pilão e, dando continuidade ao deslocamento, se acerca da cabana mais próxima do ponto de vista do espectador. Ao "tocar" a parede da cabana, há uma transição com sobreposição de imagens para a cena seguinte, que já mostra o interior da mesma com uma gestante prestes a dar à luz, sentada ao chão.

A partir dessa transição para dentro da cabana, começa o diálogo entre ela e o seu filho. Do ventre da mãe, Kiriku pede: "mãe, quero nascer", ao que ela retruca: "uma criança que fala na barriga de sua mãe pode nascer sozinha”. Em reação à resposta da mãe, Kiriku sai do ventre por conta própria, corta o cordão umbilical e anuncia: "eu me chamo Kiriku”. Logo em seguida pede: "mãe, me lave!” e a genitora devolve: "uma 
criança que nasce sozinha se lava sozinha". Mais uma vez o filho reage correndo para uma bacia d'água ali perto. Enquanto toma banho, ouve o pedido de sua mãe para poupar água por conta da maldição lançada pela feiticeira Karabá e pergunta por seus familiares, momento em que toma ciência de que foram todos comidos ao lutarem contra a feiticeira, que os seus conterrâneos acreditavam ser a responsável por secar a fonte de água da tribo. A mãe explica ao filho que o seu tio, o último jovem do povoado ainda vivo, está a caminho de mais uma tentativa de combater a feiticeira, motivo pelo qual, num reflexo rápido, diz dever ajudá-lo e sai da cabana a fim de encontrar o guerreiro solitário.

A partir da descrição dessa sequência, passaremos à observação dela enquanto parte representativa da enunciação fílmica. Antes mesmo do fade in da primeira imagem, ainda com os créditos iniciais do filme sendo exibidos, ouve-se um som de peças de madeira batendo, o que, ainda que de modo um tanto vago, remete a ambientes rústicos. Quando a primeira tomada toma forma, uma música instrumental melancólica, aparentemente tocada em harpa ou alaúde, junta-se ao som das batidas. Ao mostrar uma vista panorâmica da tribo, essa tomada já demonstra imagética e sonoramente o espaço no qual a história irá se passar, o que contribui para a demarcação parcial de um contexto social ante o espectador.

Nesse momento, percebe-se as características arquitetônicas das moradias e a paisagem na qual estão localizadas e, ao se deparar com esse primeiro lance, o espectador começa a apreender o contexto em que a trama ocorrerá. $\mathrm{O}$ baobá que figura quase em primeiro plano, sendo uma árvore representativa do continente africano, ajuda a situar de forma ainda mais particular as posições discursivas dos enunciatários e, junto com os demais elementos mobilizados, permite o estabelecimento de algumas relações entre o meio e os personagens, assim como fornece os primeiros subsídios à formulação de hipóteses sobre a trama que irá se desenrolar.

O projeto enunciativo do filme se dá de forma sintética nesses primeiros minutos, como uma introdução, e foi pensado por seus enunciadores para representar informações que contextualizam o enunciatário, direcionando-o a construções de sentido esperadas pelos que o produziram. Assim, a associação entre os componentes exclusivamente audiovisuais dessa tomada possibilita a compreensão de que a história se passará numa pequena aldeia cujos membros são sujeitos pertencentes a um meio étnico representativo de culturas africanas.

Enfatizando o caráter verbivocovisual do enunciado, notamos que esses primeiros instantes totalmente destituídos de linguagem verbal expressam de alguma forma remissões a um lugar sócio discursivo que suscitam alguma reação do espectador. Ainda que tal reação seja apenas um questionamento, uma dúvida ou mesmo uma incompreensão, essa dinâmica intersubjetiva já revestiu esses signos de roupagem enunciativa, já que são atravessados por sujeitos cuja participação na sua gênese os reveste de um projeto enunciativo enformado com vistas a um público. É nesse sentido que os itens que compõem o cenário funcionam como signos que, embora não linguísticos, podem dizer tanto quanto qualquer expressão verbal.

Cabe ressaltar que, muito embora a enunciação fílmica demarque lugares de enunciação que transcendam os personagens, não podemos dizer nesse caso que o segmento de filme analisado, e nem mesmo ele na íntegra, permite o estabelecimento de 
relações imediatas com os lugares enunciativos dos que o conceberam. Esses últimos, em realidade, são pertencentes a contextos completamente diferentes do retratado na obra, pois lembremos que o longa é uma produção franco-belga. Desse modo, os lugares sociodiscursivos desses enunciadores se mostram de forma verbal e explícita apenas nos créditos do filme, porém é óbvio que as suas escolhas ao longo da produção se traduzem na articulação de todos os elementos verbivocovisuais que o compõem. No entanto, o resultado provisoriamente acabado dessas escolhas promove um diálogo que parece se dar diretamente entre os personagens e o espectador. Há, portanto, dois planos de enunciação interpenetrados: os do filme enquanto todo "acabado" e os dos personagens com os quais os espectadores tendem a interagir de modo direto, esses últimos também enunciadores.

Se na primeira parte da sequência, composta de atributos caracterizadores de uma situação e de um contexto, lança-se mão de materialidades sígnicas não verbais capazes de prover de informações importantes sobre eles e mesmo sobre os personagens que serão logo introduzidos, é de se esperar que, no encadeamento dos lances seguintes, a articulação dessas semioses aos diálogos verbais entre Kiriku e a sua mãe se dê de forma congruente e demonstre ainda com mais precisão os lugares sociodiscursivos desses personagens e do longa como um todo. Levando-se em conta essa inter-relação do verbal com o não verbal, vamos observar agora as cenas em torno do parto de Kiriku.

A partir da primeira cena a retratar o interior da cabana, já se tem uma noção das privações que a tribo sofre. Praticamente desprovida de mobília, a cabana possui apenas um móvel sobre o qual há uma cabaça e no qual a mãe de Kiriku está recostada. Ou seja, temos nesse instante a informação visualmente dada de que aquela mulher vive em um meio bastante simples em termos materiais, o que é reforçado assim que Kiriku nasce e vai se banhar, pois ao entrar na bacia, sua mãe pede para que não desperdice água, visto que a feiticeira secou a fonte de água de que se serviam. Aqui se percebe com clareza o verbal e o não verbal em diálogo, expressando a miséria enfrentada pela tribo a partir da situação dialogal entre Kiriku e sua mãe. Ao pedido da mãe, Kiriku, que a princípio se divertia agitadamente na água, se aquieta, olha ao seu redor e começa a lançar uma série de perguntas àquela que lhe deu à luz.

$\mathrm{Na}$ sequência de tomadas que circunscreve o nascimento do menino, o semblante e os gestos da mãe do pequeno herói pronunciam-se tanto quanto as coisas que diz. Ao explicar a Kiriku que quase todos os homens da tribo foram comidos pela feiticeira, o seu olhar cabisbaixo e o seu tom de voz triste demonstram conjuntamente as adversidades pelas quais passam. Em outras palavras, a mulher melancólica da animação expressa verbivocovisualmente, por meio de feições, posturas e dizeres, o seu sentimento diante do que sucedeu ao local em que vive.

Nessa circunstância, seu rosto é mostrado em close a cada vez que fala, de modo a dar destaque ao olhar esmorecido que lança para as lembranças das fatalidades ocorridas, ao passo que a sua voz baixa e enfraquecida demonstra sonoramente os seus sentimentos. Ao mesmo tempo, quando começa a perguntar inquieto pelos homens de sua família, Kiriku gradualmente muda de entonação e de postura diante das respostas desanimadoras que recebe de sua mãe. A cada réplica negativa, o menino se encolhe e baixa o tom de voz, o que é também destacado com planos mais fechados e expressivos. 
O diálogo entre o dito e o visualizado continua e, quando a sua mãe menciona que ainda há um tio seu vivo, o bebê imediatamente recupera o ânimo e parte para ação.

Nesse momento, é interessante notarmos como a cena está intersemioticamente articulada. Ao ouvir sua mãe dizer sobre o seu último irmão vivo, kiriku, num sobressalto, se apoia na borda da bacia e pergunta impaciente: "e onde ele está?", em mais uma tomada semifechada. Nesse instante, o menino também expressa corporalmente a sua surpresa e impaciência diante da nova informação. Sua mãe, agora com um olhar de esperança para o horizonte, ressaltado pela emulação de uma aproximação repentina através de um movimento de "zoom", afirma que ele está na estrada dos Flamboyants a caminho das terras da feiticeira. Esse é o instante em que o pequeno se levanta dentro da bacia, se vira de frente para o espectador e salta dela, enquanto afirma com veemência: "então, eu devo ajudá-lo". Há então um corte para a cena seguinte, em um novo plano aberto, no qual sai apressadamente da cabana para alcançar o seu tio. Os cortes que delimitam essa última cena são tão rápidos quanto o ímpeto de Kiriku, assim como refletem a brevidade da sua última fala.

Como já vimos, um enunciado é responsivo a algo que o provoca e, ao mesmo tempo, suscita respostas. No recorte analisado, o protagonista Kiriku utiliza-se da palavra antes mesmo de nascer e, assim como na vida, suas palavras aparecem ora como forma de questionamento ora como forma de intervenção. Nesse sentido, o protagonista participa de enunciações carregadas semanticamente pelo diálogo estabelecido com a mãe em turnos de fala encadeados que se respondem mutuamente.

Nesse viés, as reações a cada dizer de sua mãe se traduzem tanto em réplicas verbais quanto em ações diretas de cunho não verbal, mas, nem por isso, menos passíveis de adquirirem sentidos. Essas reações não verbais, sejam manifestas em gestos, sejam em sons, são permeadas pela força da alteridade e, por isso, adquirem caráter de enunciado. No plano da representação cinematográfica, a própria sequência das tomadas que, coordenadas numa construção coerente, dialogam entre si, podem ser pensadas como corrente enunciativa não só dentro da trama, pois consideradas no todo cinematográfico em que figuram, além de dialogarem entre si, simultaneamente extrapolam o próprio filme, respondendo aos estímulos dos que o conceberam e provocando os que o assistem, fazendo circular diferentes linguagens interconstituídas de forma intrínseca.

Trazendo os postulados do Círculo sobre enunciação para o filme, pensemos no seu endereçamento. Como qualquer enunciado, o filme foi formulado em função de seus interlocutores e de um contexto de circulação. A partir de uma vontade enunciativa, o longa foi produzido segundo uma dada perspectiva. Na sua complexidade, a produção põe em diálogo uma série de elementos verbivocovisuais. Consequentemente, esse todo audiovisual sofisticado é de natureza heterodiscursiva, já que, sendo enunciado, inescapavelmente reúne dizeres e contradizeres, explícitos ou não, a respeito do que retrata e circula por espaços igualmente heterogêneos.

Um ponto interessante a ser observado, é que, em se tratando de um longa de animação, gênero geralmente mais apreciado por crianças, os seus constituintes não verbais são justamente os que trazem em si maior montante de informações, o que reforça o peso do contexto no enunciado cinematográfico. É pelo audiovisual que a determinação sociodiscursiva do espectador na trama é possível. Para além dos diálogos verbais, o 
encadeamento das ações valorativas de Kiriku e de sua mãe, aliadas aos juízos de valor inerentes à produção do filme, se fazem mais visíveis no plano não verbal. Dadas essas características, o excerto investigado tem uma carga semântica fundamentalmente advinda do diálogo entre o verbal e o não verbal.

Aprofundando-nos mais na sequência escolhida, percebemos que as escolhas estéticas dos responsáveis pela produção do filme se mostram de forma particular na configuração do gênero. Essas marcas pessoais únicas englobam desde questões técnicas até a criação artística propriamente dita e se exprimem em enquadramentos, paletas de cores, características físicas, comportamentais, axiológicas de cada personagem, estilos de traço do desenho, composição da trilha sonora, do enredo etc. Então, a partir do trecho em análise, tem-se uma amostra desses três elementos principais constitutivos dos enunciados.

O conteúdo temático da cena, embora específico, norteia toda a trama, já que caracteriza o estado de coisas em torno do qual ela se desenvolve, alinhando-se à temática do filme no geral. Assim, o diálogo através do qual a mãe narra a Kiriku o que se passou na tribo, sucedendo ao plano geral em que a comunidade é retratada de início e em diálogo com toda a sequência que o acompanha, introduz elementos fantásticos, tais como feitiços e uma criança com capacidades incríveis, circunscrevendo como tema no circuito da sua enunciação o registro artístico e a valorização, voltados a um público predominantemente infantil, de um mito africano largamente difundido e apreciado.

Quanto ao estilo do longa, é possível que nem todas as suas manifestações sejam compiláveis, já que ele está ligado a uma grande quantidade de aspectos íntimos do grupo de sujeitos envolvidos na produção enunciativa. Contudo, pode-se seguramente afirmar que o estilo e a decorrente singularidade que confere a esse enunciado/enunciação está de alguma forma presente em todas as suas dimensões. Muito embora não se possa explicar a razão de cada detalhe elencado, é fato que o emprego de cada um deles é de natureza estilística. Bakhtin afirma que "a própria escolha de uma determinada forma gramatical pelo falante é um ato estilístico" (2016, p. 22). Se estendemos aqui a noção de palavra, em sentido amplo, ao audiovisual, naturalmente pode-se entender que as cores, a ambientação, a opção pelas vozes que dublam os personagens, a seleção das músicas que constituem a trilha sonora, o recurso a certas maneiras de enquadrar, de editar, de roteirizar, assim como a própria decisão de adaptar uma tradição oral africana, refletem inequivocamente a vontade enunciativa e as particularidades dos seus criadores.

Todo esse percurso valorativo também se faz transparecer na construção composicional do filme. No entanto, esse quesito está mais diretamente ligado à arquitetônica à qual o filme está conformado. No que tange esse aspecto, o teor da narrativa, o seu endereçamento e a sua concretização sob um gênero cinematográfico infantil justificam a escolha por se produzir um longa de animação e todos os desdobramentos dessa escolha. Daí a forma lúdica como certas ações, dizeres e sons se articulam, como no exato momento em que Kiriku tem o rompante de ir atrás do seu tio. Por exemplo, as mesmas cores que se exprimem nuances estilísticas também estão relacionadas à composição de uma animação voltada às crianças, assim como a relativa simplicidade dos diálogos é adequada ao perfil do público. 
Da mesma forma como o Círculo de Bakhtin reconhece os textos verbais, os filmes podem ser entendidos como "textos" multissemióticos e, por esse caminho, têm muito a contribuir para a elucidação do quanto as semioses não verbais se equiparam às palavras. Em seu estudo dedicado à relevância do texto nas ciências humanas, constante da obra Gêneros do discurso, Bakhtin coloca o seguinte: "se concebe o texto no sentido amplo como qualquer conjunto coerente de signos, a ciência das artes (a musicologia, a teoria e a história das artes plásticas) opera com textos (obras de arte)" (2016, p. 71). Não deixemos de ressaltar que nesse estudo Bakhtin enxerga o texto na condição de enunciado, ou como já discutido, enquanto elo de uma corrente enunciativa. Ao transpor essa conceituação de texto a todas as materialidades sígnicas, ele, por extensão, atribui o status de enunciação às demais formas de manifestação artística.

Portanto, o filme de animação é um objeto estético farto de elementos a serem pesquisados à luz do referencial bakhtiniano. Disso resulta a presente observação sobre os itens não verbais do fragmento do filme, pois eles podem perfeitamente ser destacados visando ao fomento de discussões relativas à natureza enunciativa das semioses características desse gênero discursivo.

\section{CONSIDERAÇÕES FINAIS}

O trabalho apresentado teve como proposta a análise dos elementos não verbais constitutivos de um filme de animação, visando demonstrar como os mesmos, na qualidade de materialidades sígnicas e, portanto, sujeitas à avaliação ideológica, figuram na composição de um longa. Neste intuito, mobilizamos o conceito de enunciado/enunciação para esclarecermos em que medida tais signos, uma vez inseridos no processo enunciativo fílmico, atuam em nome da execução de projetos de sentido dotados dos mesmos potenciais valorativos presentes nos signos e enunciados verbais, enfatizando assim a fertilidade semântica dessas materialidades integradas nesse gênero audiovisual. Em seguida, trouxemos considerações quanto à dimensão enunciativa dos filmes, pensando no circuito da produção, circulação e recepção deles, assim como nos diálogos que estabelecem com os espectadores, de modo a revelarmos o entrecruzamento de lugares socioideológicos elucidativos de realidades sociais diversas proporcionados pela sua exibição.

Ao preconizar a manifestação da linguagem a partir dos seus empregos em situações interativas reais e sob a forma de intercâmbios de enunciações concretos, destacamos ainda que a Filosofia da Linguagem nos instrumentaliza para a análise em profundidade das concepções de mundo e das relações de poder em jogo nas dinâmicas enunciativas, sejam elas de que gênero for, uma vez que a observação das linguagens com base nessa concepção passa inevitavelmente pelos juízos de valor de sujeitos acerca de todos os aspectos de uma interação discursiva. Nesse sentido, a passagem do longa estudada nos mostra que o não verbal, articulado ou não ao verbal, é dotado do mesmo potencial semântico e axiológico que este último e, assim sendo, é também ideológico, pois resulta do embate entre lugares sociodiscursivos de compreensão. Figurando em processos enunciativos, tais elementos adquirem status equivalente ao do signo linguístico, podendo igualmente responder e desencadear respostas entre os sujeitos participantes do contínuo discursivo, num intercâmbio em que adquirem sentidos em razão do diálogo entre pontos de vista reveladores, entre outros aspectos, de representações acerca da temática sobre a qual enunciam. 
Bakhtin afirma que "o elemento lógico-objetal da palavra se torna o palco do encontro de interlocutores, a arena da formação dos seus pontos de vista e apreciações" (2016, p. 123). Tomando-se o excerto do filme como amostra do processo/produto da conexão de materialidades sígnicas multiformes, pode-se pressupor toda uma série de lutas dialógicas que conjuntos de signos tão distintos entre si podem desencadear.

$\mathrm{Na}$ sua orientação social, os itens não verbais do excerto selecionado, interrelacionados ao verbal, dialogam com o espectador conjuntamente, situando sociodiscursivamente enunciadores e enunciatários. No circuito da sua produção até a sua recepção, a sequência consiste em parte de uma unidade discursiva verbivocovisual cujas particularidades podem ser investigadas em nome de uma melhor compreensão não só da natureza e das condições de materialização de signos tão ricos semanticamente quanto itens lexicais, mas das implicações políticas que o entendimento da luta dialógica que esses processos pressupõem pode proporcionar aos sujeitos em termos de emancipação social.

Portanto, todo material simbólico capaz de adquirir plenitude enunciativa igualase à palavra. Se qualquer enunciação somente tem sentido na sua realização em meios sociodiscursivos, de enunciadores para enunciatários, a verbivocovisualidade presente no gênero fílmico possibilita a construção de sentidos para as linguagens que o compõem exatamente da mesma forma que as enunciações exclusivamente verbais. Isso nos indica que, do ponto de vista enunciativo, gêneros marcadamente verbivocovisuais requerem a mesma atenção dada aos enunciados pertencentes a gêneros expressamente verbais, o que nos leva a pensar nos desdobramentos socioeducacionais com que essa abordagem pode contribuir.

\section{REFERÊNCIAS}

BAKHTIN, Mikhail. Estética da criação verbal. São Paulo: WMF Martins Fontes, 2011.

BAKHTIN, Mikhail. M. Os gêneros do discurso. São Paulo: Editora 34, 2016.

BAKHTIN, Mikhail. Para uma filosofia do Ato. São Carlos: Pedro \& João Editores, 2010.

PAULA, Luciane de; SERNI, Nicole Mioni. A vida na arte: a verbivocovisualidade do gênero filme musical. 2017.

RODRIGUES, Cristiano José. Os sujeitos do diálogo: personagens, documentaristas e espectadores. In: FREITAS, Maria Tereza de Assunção; Silva, Alessandra. Bakhtin. São Paulo: Parábola. 2017.

VOLOCHINOV, Valentin N. A construção da enunciação. In: VOLOCHINOV, Valentin N. A construção da enunciação e outros ensaios. São Carlos: Pedro e João. Editora, 2013.

VOLOCHINOV, Valentin N. Marxismo e filosofia da linguagem. Problemas fundamentais do método sociológico na ciência da linguagem. São Paulo: Editora 34, 2017. 
Artigo recebido em: jul. de 2020.

Aprovado e revisado em: out. de 2020.

Publicado em: dez. de 2020.

Para citar este texto:

OLIVEIRA, Leonardo de; MESQUITA, Lucimara Grando. Os Signos Não Verbais enquanto Palavras na Constituição Enunciativa do Gênero Fílmico. Entremeios [Revista de Estudos do Discurso, ISSN 2179-3514, on-line, www.entremeios.inf.br], Seção Estudos, Programa de Pós-Graduação em Ciências da Linguagem (PPGCL), Universidade do Vale do Sapucaí (UNIVÁS), Pouso Alegre (MG), vol. 22, p. 171-186, jul. - dez. 2020.

DOI: http://dx.doi.org/10.20337/ISSN2179-3514revistaENTREMEIOSvol22pagina171a186 